\title{
Influence of Phostrade Ca on Color Development and Anthocyanin Content of 'Braeburn' Apple (Malus domestica Borkh.)
}

Jan Bizjak ${ }^{1}$, Nika Weber, Maja Mikulic-Petkovsek, Ana Slatnar, and Franci Stampar University of Ljubljana, Biotechnical Faculty, Department of Agronomy, Chair for Fruit, Wine and Vegetable Growing, Jamnikarjeva 101, SI-1000 Ljubljana, Slovenia

\section{Zobayer Alam, Karl Stich, and Heidi Halbwirth \\ Technical University of Vienna, Institute for Chemical Engineering, Getreidemarkt 9/1665, A-1060 Vienna, Austria}

\author{
Robert Veberic \\ University of Ljubljana, Biotechnical Faculty, Department of Agronomy, \\ Chair for Fruit, Wine and Vegetable Growing, Jamnikarjeva 101, SI-1000 \\ Ljubljana, Slovenia
}

Additional index words. flavonoids, flavonols, fruit color, sugars, foliar application

\begin{abstract}
The influence of two foliar applications of Phostrade Ca, which contains high concentrations of phosphorus and minor amounts of calcium and nitrogen, on color development and selected primary and secondary metabolites was investigated during advanced maturation of 'Braeburn' apple. Changes of hydroxycinnamic acids, flavanols, dihydrochalcones, flavonols, and anthocyanins were monitored six times during the advanced ripening until technological maturity of the fruits. Additionally, the changes in the chromatic values $a^{*}, h^{\circ}$, and the lightness coefficient $L^{*}$ were recorded weekly. The colorimetric parameters showed a significant difference in the intensity of red coloration between the treated and untreated apples. Spraying with Phostrade Ca also resulted in a significant increase in most individual sugars, total sugars, and concentration of anthocyanins and flavonols. Moreover, the amount of phosphorus $(P)$ in the treated leaves was increased. However, the total phenolic content and accumulation of other classes of flavonoids such as hydroxycinnamic acids, flavonols, and dihydrochalcones were not influenced. Phostrade Ca treatment significantly increased dihydroflavonol 4-reductase (DFR) and slightly flavanone-3-hydroxylase (FHT) activity, which were correlated with anthocyanin synthesis but had no effect on phenylalanine ammonia lyase (PAL) and chalcone synthase/chalcone isomerase (CHS/CHI) activity. The results indicate that two foliar applications of Phostrade $\mathrm{Ca}$ late in the growing season represent an effective way to improve the color of 'Braeburn' apples at commercial harvest.
\end{abstract}

An intense red skin color is an important quality parameter for consumers when purchasing apples and can contribute much to a higher market value of the fruit. In apple fruits, red color is mainly the consequence of the presence of anthocyanins, which accumulate as granules in the vacuoles (Bae and $\mathrm{Kim}, 2006$ ), but flavonols (quercetin 3-Oglycosides) and proanthocyanidins also have

Received for publication 8 Nov. 2012. Accepted for publication 19 Dec. 2012.

This investigation was part of the Horticulture Program P4-0013-0481 and the we thank the Slovenian Ministry of Higher Education, Science and Technology for financial support. At the same time we also thank JURANA D.O.O. for providing us with the Phostrade Ca fertilizer.

${ }^{1}$ To whom reprint requests should be addressed; e-mail: jan.bizjak@bf.uni-lj.si. some influence (Lister et al., 1994). Anthocyanin accumulation is usually restricted to the skin of apple. The pigments provide essential cultivar differentiation for consumers and are implicated in the health attributes of apple fruit (Espley et al., 2007). Fruit color and biosynthesis of anthocyanins can be regulated by light and ethylene (Saure, 1990), temperature (Arakawa, 1991), the use of a hail net and reflective foil (Blanke, 2008; Jakopic et al., 2010), nitrogen fertilization (Treutter, 2001), wounding (Chalmers and Faragher, 1977), bagging (Hudina and Stampar, 2011), irrigation cooling (Iglesias et al., 2002), and different chemical applications (Whale et al., 2008). Moreover, color development also depends on a regular supply of sugars in the fruit (Lueangprasert et al., 2010).

'Braeburn' Hillwell is classified as a striped red-colored apple cultivar. Striped fruits are less red on average than blushed fruits (Telias et al., 2008); therefore, it is useful for the growers to have a variety of techniques available that can help them to achieve better coloration, especially in regions and years with poor coloring conditions.

Phostrade $\mathrm{Ca}(\mathrm{Pho} \mathrm{Ca}$ ) is a concentrated liquid $\mathrm{P}$ solution containing calcium and nitrogen recommended for foliar application at the beginning of fruit formation and during fruit enlargement and maturation. P-containing compounds have already been documented to increase anthocyanin concentration and improve fruit color (Gómez-Cordovés et al., 1996; Larrigaudiere et al., 1996; Li et al., 2002). The use of Seniphos seems to be promising because it stimulates anthocyanin accumulation without activation of ethylene production and advanced ripening (Larrigaudiere et al., 1996). Furthermore, it does not affect the storage life as reported for ethephon (Li et al., 2002). Li et al. (2002) suggested that increased PAL and CHI activity contributed to the observed improvement in anthocyanin formation and in red coloration of apple skin. The rapid increase of PAL activity directly related to the increase of anthocyanin biosynthesis was reported also by Larrigaudiere et al. (1996). However, the mode of action by which these compounds affect color development has been poorly investigated and remains unclear.

The purpose of our work was to investigate if two foliar applications of P-containing compound Pho Ca during advanced maturation can enhance anthocyanin accumulation and consequently improve red coloration of 'Braeburn' apples. Moreover, we were also interested in evaluating the impact of the Pho $\mathrm{Ca}$ on the total phenolic content and some other phenolic compounds belonging to different phenolic groups. To get a more detailed insight into the action of Pho $\mathrm{Ca}$ in apple skin, changes in sugars and enzyme activity of several different enzymes were also recorded. The results should contribute to an improved understanding of the mechanism, by which P-containing compounds affect the red coloration of apples.

\section{Materials and Methods}

Plant materials. The experiment was carried out in 2011 on 10-year-old trees of striped 'Braeburn' (Malus domestica Borkh.) cultivar clone Hillwell grafted on M9 rootstock, grown according to the system of integrated production at the Ljubljana location (lat. $46^{\circ} 2^{\prime} \mathrm{N}$, long. $14^{\circ} 28^{\prime} \mathrm{E}$ ). On 9 Sept. ( 5 weeks before commercial harvest), $\mathrm{Pho} \mathrm{Ca}$ (23.6\% w/w $\mathrm{P}_{2} \mathrm{O}_{5}, 4.3 \% \mathrm{w} / \mathrm{w} \mathrm{CaO}$, and $3 \%$ $\mathrm{w} / \mathrm{w}$ nitrogen) was applied at a concentration of $0.5 \%$ (company recommendation). Control trees were sprayed with water. The second spraying was done $14 \mathrm{~d}$ later on 23 Sept.

Fruit color. The skin color was measured using a portable colorimeter (CR-200 b Chroma; Minolta, Osaka, Japan) and recording $L^{*}, a^{*}$, and $b^{*}$ color coordinates on the fruit surface (McGuire, 1992). Before measuring, the colorimeter was calibrated with a white standard calibration plate. The data were expressed also 
in hue angle, calculated as $\left(\tan ^{-1} b^{*} / a^{*}\right)$ in degrees from 0 to 360 , where $0^{\circ}=\operatorname{red}, 90^{\circ}=$ yellow, $180^{\circ}=$ green, and $270^{\circ}=$ blue (McGuire, 1992).

Fruit color was measured starting on 9 Sept. (sampling date 0) and continued weekly until commercial harvest of the fruit (sampling date 5). At each sampling date, color measurements were made on 20 fruit from the outside of the tree canopy (four fruit per tree) up to a height of $2 \mathrm{~m}$ from the ground. Fruit were randomly selected before the first Pho $\mathrm{Ca}$ application (sampling date 0).

Fruit sampling. Fruit sampling started on 9 Sept. (before the first spraying) and was performed weekly until commercial harvest, which was determined using the starch iodine test. At that time the value of firmness was $9.5 \mathrm{~kg} \cdot \mathrm{cm}^{-2}$ and the starch index was 2.7 . At each sampling date, 15 fruits were randomly harvested and combined in five samples with three fruit per sample $(n=5)$. Immediately after harvest, apples were transported to the laboratory, where the tissue of samples was frozen in liquid nitrogen to prevent oxidation of phenolic substances and stored at $-20{ }^{\circ} \mathrm{C}$ until the preparation of the samples. For the determination of enzyme activity, one part of the apple skin was stored frozen at $-80{ }^{\circ} \mathrm{C}$ until enzymatic analysis.

Analysis of individual sugars and organic acids. Sucrose, glucose, fructose and sorbitol, and malic and citric acids were analyzed in the whole edible part of the fruit according to Mikulic-Petkovsek et al. (2007). For the extraction of individual sugars and organic acids, $10 \mathrm{~g}$ of the fresh weight of each sample was homogenized in $50 \mathrm{~mL}$ of bidistilled water using Ultra-Turrax T-25 (Ika-Labortechnik, Stauden, Germany). Samples were left for $30 \mathrm{~min}$ at room temperature and stirred frequently. After extraction, the homogenate was centrifuged (Eppendorf 5810 R Centrifuge, Hamburg, Germany) at 10,000 rpm for $5 \mathrm{~min}$ at $4{ }^{\circ} \mathrm{C}$. The supernatants were filtered through the $0.45-\mu \mathrm{m}$ cellulose ester filter (Macherey-Nagel, Düren, Germany), transferred into a vial, and $20 \mu \mathrm{L}$ of the sample was used for analysis. The analysis of sugars (fructose, glucose, and sucrose), sorbitol, malic, and citric acid content was carried out using high-performance liquid chromatography (HPLC) from the Thermo Separation Products equipment (Mikulic-Petkovsek et al., 2007).

Separation of sugars and sorbitol was carried out using a Rezex RCM-monosaccharide column $(300 \times 7.8 \mathrm{~mm}$; Phenomenex, Torrance, CA) with a flow of $0.6 \mathrm{~mL} \cdot \mathrm{min}^{-1}$ and column temperature maintained at $65^{\circ} \mathrm{C}$. The mobile phase was bidistilled water; the total run time was $30 \mathrm{~min}$, and a refractive index detector Shodex RI-71 was used to monitor the eluted carbohydrates as described by Mikulic-Petkovsek et al. (2007). Organic acids were analyzed using a RezexROAorganic acid column $(300 \times 7.8 \mathrm{~mm}$; Phenomenex) and the ultraviolet detector set at $210 \mathrm{~nm}$ with a flow of $0.6 \mathrm{~mL} \cdot \mathrm{min}^{-1}$ maintaining the column temperature at $65^{\circ} \mathrm{C}$. The duration of the analysis was $30 \mathrm{~min}$.
The concentrations of carbohydrates and organic acids were calculated with the help of corresponding external standards. The concentrations were expressed in $\mathrm{g} \cdot \mathrm{kg}^{-1}$ fresh weight (FW).

Chemicals. For the quantification of phenolic compounds, the following standards were used: chlorogenic acid (5-caffeoylquinic acid), phloretin, and rutin (quercetin 3-O rutinoside) from Sigma Aldrich Chemie (Steinheim, Germany); cyanidin 3-O-galactoside chloride, quercetin 3-O-rhamnoside, quercetin 3-O-galactoside, quercetin 3-O-glucoside, (-)-epicatechin, $p$-coumaric acid, procyanidin B2, and phloridzin dihydrate from Fluka Chemie (Buchs, Switzerland); quercetin 3$O$-arabinofuranoside and quercetin 3-Oxyloside from Apin Chemicals (Abingdon, U.K.); and (+)-catechin from Roth (Karlsruhe, Germany). Methanol for the extraction of phenolics was acquired from Sigma Aldrich Chemie. Chemicals for the mobile phases were the HPLC-mass spectrometry (MS)grade acetonitrile and formic acid from Fluka Chemie. Water for the mobile phase was bidistilled and purified with the Milli-Q system (Millipore, Bedford, MA). For determination of the total phenolic content, FolinCiocalteu phenol reagent (Fluka Chemie), sodium carbonate (Merck, Darmstadt, Germany), gallic acid, and ethanol (Sigma Aldrich Chemie) were used. Substrates for enzyme assays were synthesized as described (Gosch et al., 2003).

Extraction and determination of phenolic compounds. The extraction of fruit samples for phenolic compounds was done as described by Mikulic-Petkovsek et al. (2010) with some modification. Apple samples were ground to a fine powder in a mortar chilled with liquid nitrogen. Five grams of apple skin were extracted with $10 \mathrm{~mL}$ of methanol containing 3\% (v/v) formic acid and $1 \%$ (w/v) 2.6-di-tert-butyl-4-methylphenol (BHT) in a cooled ultrasonic bath for $1 \mathrm{~h}$. BHT was added to the samples to prevent oxidation. After extraction, the treated samples were centrifuged for $5 \mathrm{~min}$ at $12,000 \times \mathrm{g}$. The supernatant was filtered through a Chromafil AO-45/25 polyamide filter (Macherey-Nagel, Düren, Germany) and transferred to a vial before the injection into the HPLC system.

The individual phenolic compounds were analyzed using a Thermo Finnigan Surveyor HPLC system (Thermo Scientific, San Jose, CA) with a diode array detector at $280 \mathrm{~nm}$, $350 \mathrm{~nm}$, and $530 \mathrm{~nm}$. The hydroxycinnamic acids, dihydrochalcones, and flavonols were detected at $280 \mathrm{~nm}$, flavonols at $350 \mathrm{~nm}$, and anthocyanins at $530 \mathrm{~nm}$. For the separation of phenolic compounds, a Phenomenex HPLC column C18 $(150 \times 4.6 \mathrm{~mm}$, Gemini $3 \mu)$ protected with a Phenomenex security guard column operated at $25{ }^{\circ} \mathrm{C}$ was used. The injection volume for the fruit extract was $20 \mu \mathrm{L}$ and the flow rate maintained at $1 \mathrm{~mL} \cdot \mathrm{min}^{-1}$. The elution solvents were aqueous $1 \%$ formic acid and 5\% acetonitrile (A) and 100\% acetonitrile (B). Samples were eluted according to the linear gradient described by Marks et al. (2007): 0 to $5 \mathrm{~min}, 3 \%$ to $9 \% \mathrm{~B} ; 5$ to
$15 \mathrm{~min}, 9 \%$ to $16 \% \mathrm{~B} ; 15$ to $45 \mathrm{~min}, 16 \%$ to $50 \% \mathrm{~B} ; 45$ to $50 \mathrm{~min}, 50 \%$ isocratic; this step was followed by the washing and reconditioning of the column. The compound identification was achieved by comparing the retention times and their ultraviolet-VIS spectra from 200 to $600 \mathrm{~nm}$ as well as by the addition of an external standard. The identity of the phenolic compounds was also confirmed and quantified using a mass spectrometer (Thermo Scientific, LCQ Deca XP MAX) with an electrospray ionization operating in the negative and positive ion modes. For the analyses, full-scan data-dependent MS scanning from $\mathrm{m} / z 115$ to 2000 was used. Quantification was achieved according to the concentrations of a corresponding external standard. For the compounds lacking reference compounds, related compounds were used as standards for the quantification. Therefore, 4- $O-p$-coumaroylquinic acid was quantified in equivalents of $p$ coumaric acid, phloretin-2- $O$-xylosylglucoside in equivalents of phloridzin, quercetin 3-Oarabinopyranoside in equivalents of quercetin 3-O-arabinofuranoside, and anthocyanins (cyanidin 3-arabinoside, cyanidin 7-arabinoside, cyanidin 3-glucoside, and cyanidin 3-xyloside) were quantified in equivalents of cyanidin 3 -galactoside. Concentrations of the phenolic compounds were expressed in $\mathrm{mg} \cdot \mathrm{kg}^{-1}$ of $\mathrm{FW}$.

Determination of the total phenolic content. Extracts of the samples were obtained in the same way as for the individual phenolic compounds with the difference that no BHT was added. The total phenolic content of extracts was assessed using the FolinCiocalteau phenol reagent method, as described by Singleton and Rossi (1965). To $100 \mu \mathrm{L}$ of sample extracts, $6 \mathrm{~mL}$ of bidistilled water and $500 \mu \mathrm{L}$ of Folin-Ciocalteau reagent were added; after resting between $8 \mathrm{~s}$ and $8 \mathrm{~min}$ at room temperature, $1.5 \mathrm{~mL}$ of sodium carbonate $(20 \% \mathrm{w} / \mathrm{v})$ and $1.9 \mathrm{~mL}$ bidistilled water were added. The extracts were mixed and allowed to stand for $30 \mathrm{~min}$ at $40{ }^{\circ} \mathrm{C}$. After that the absorbance was measured in a spectrophotometer (Perkin Elmer, ultraviolet/VIS Lambda Bio 20) at $765 \mathrm{~nm}$. A mixture of water and reagents was used as a blank. The total phenolic content was expressed as gallic acid equivalents in $\mathrm{mg} \cdot \mathrm{kg}^{-1} \mathrm{FW}$. Absorption was measured in three replications.

Analysis and determination of phosphorus and calcium concentration in apple leaves. Samples for leaf $\mathrm{P}$ and calcium $(\mathrm{Ca})$ concentrations were taken three times during the advanced ripening: on 9 Sept. (before the first application of Pho Ca), on 30 Sept. (1 week after the second application), and on 14 Oct. 2011 (commercial harvest). A combined sample of 10 fully developed, healthy leaves per tree was analyzed in three repetitions for each treatment. Plant samples had been washed first in water to remove surface residues and then dried at $40{ }^{\circ} \mathrm{C}$ until constant weight was achieved. The sample was reduced to ashes in a muffle furnace at $550 \pm 15^{\circ} \mathrm{C}$. The ash was then dissolved in hydrochloric acid and the silica compounds present removed by precipitation and filtration. The filtrate was diluted 
to the desired volume $(100 \mathrm{~mL})$ with demineralized water (Milli Q; Millipore).

For the determination of $\mathrm{P}$, an aliquot portion of the filtrate was mixed with molybdovanadate reagent and the absorbance of the yellow complex was measured at a wavelength of $430 \mathrm{~nm}$ on the ultraviolet/VIS spectrometer (Cary 100; Varian). The absorbance of the sample was compared with the absorbance of standards with a known concentration to determine leaf $\mathrm{P}$ concentration. Calcium was determined by flame atomic absorption spectrometry (Analyst 800; Perkin Elmer). The absorbance of $\mathrm{Ca}$ in the sample solution was determined by comparison with the absorbance of calibration solutions. The ionization and chemical interferences were controlled by the addition of caesium and lanthanum buffer solutions to standards and samples.

Extraction and assay of enzyme. Buffers used were Buffer A [phenylalanine ammonia lyase-PAL assays; electrical conductivity (EC) 4.3.1.5]: $0.1 \mathrm{M} \mathrm{H}_{3} \mathrm{BO}_{3}+0.4 \% \mathrm{Na}-$ ascorbate, $\mathrm{pH}$ 8.5; Buffer $\mathrm{B}$ (CHS/CHI assays; CHS; EC 3.2.1.74; CHI; EC 3.2.1.14): $0.1 \mathrm{M} \mathrm{KPi}\left(\mathrm{KH}_{2} \mathrm{PO}_{4} / \mathrm{K}_{2} \mathrm{HPO}_{4}\right)+0.4 \% \mathrm{Na}-$ ascorbate, pH 7.0; Buffer C (FHT assays; FHT; EC 1.14.11.9): 0.1 M Tris/HCl + 0.4\% Na-ascorbate, $\mathrm{pH}$ 7.25; and Buffer D (DFR assays; DFR; EC 1.1.1.219): $0.1 \mathrm{M} \mathrm{KPi}+$ $0.4 \%$ Na-ascorbate, $\mathrm{pH} 6.8$.

Enzyme preparations. Shock-frozen apple skin was ground to powder with liquid nitrogen.
A total of $1 \mathrm{~g}$ fine apple skin powder was homogenized with $0.5 \mathrm{~g}$ quartz sand, $0.5 \mathrm{~g}$ Polyclar AT, and $6 \mathrm{~mL} 0.1 \mathrm{M}$ Tris $/ \mathrm{HCl}$ (containing $0.4 \% \mathrm{Na}$-ascorbate, $\mathrm{pH} 7.25$ ) in a mortar. The homogenate was centrifuged for $10 \mathrm{~min}$ at $4{ }^{\circ} \mathrm{C}$ and $10,000 \mathrm{~g}$. To remove low-molecular compounds, $400 \mu \mathrm{L}$ of supernatant was passed through a gel chromatography column (Sephadex G25 medium).

Analyses of enzyme activity. Enzyme assays were performed as previously described (Slatnar et al., 2010) using the assay conditions optimized for apple skin. Values on each sampling date represent an average of four independent biological repetitions for each treatment. Enzyme activity for PAL, CHS/CHI, FHT, and DFR was calculated and expressed in nkat. $\mathrm{g}^{-1} \mathrm{FW}$.

Statistics. Statistical analysis was conducted using the Statgraphics Plus 4.0 program (Manugistics. Inc., Rockville, MD). All data were subjected to two-way analysis of variance including the treatment and maturation time as factors. Significant differences among treatments were determined using the least significant difference test, whereas the differences between sampling dates were tested using the Duncan test. In both cases, the significance level was 0.05 . The relationships were tested at $P \leq 0.05$. For the determination of the association between the sucrose/glucose and total anthocyanins and enzyme activity and total anthocyanins, Pearson's correlation coefficient was calculated.

\section{Results}

To evaluate the potential of Pho Ca applications of enhancing red coloration during advanced ripening, the changes in the colorimetric parameters $a, L^{*}$, and hue angle $\left(h^{\circ}\right)$ were monitored.

The hue angle $\left(h^{\circ}\right)$, the best indicator of color changes during fruit development (Greer, 2005), decreased during the advanced ripening, indicating a greater intensity of red color (Fig. 1A). Treatment with Pho $\mathrm{Ca}$ significantly influenced the hue angle. During the 5 weeks of ripening, the average values for the treated apples were 41.5 and for the control $46.1(P=0.0002)$. Similar effect was also detected for the parameter $a^{*}$, which increased during the fruit ripening (Fig. 1B). In this parameter, the average values were 26.9 for treated apples and 23.5 for the control $(P=0.00001)$. Furthermore, the Pho $\mathrm{Ca}$ treatment also influenced the parameter $L^{*}$, which decreased during the advanced maturity, indicating darker fruit skin (Fig. 1C). During 5 weeks of ripening, the average $L^{*}$ value of the treated apples was 44.68, whereas the average value of the control was 46.1. However, the effect of the treatment was slightly less significant $(P=0.008)$ in this parameter.

The anthocyanin concentration increased during the advanced ripening (Fig. 1D). The highest concentration of total anthocyanins was measured at commercial harvest, when
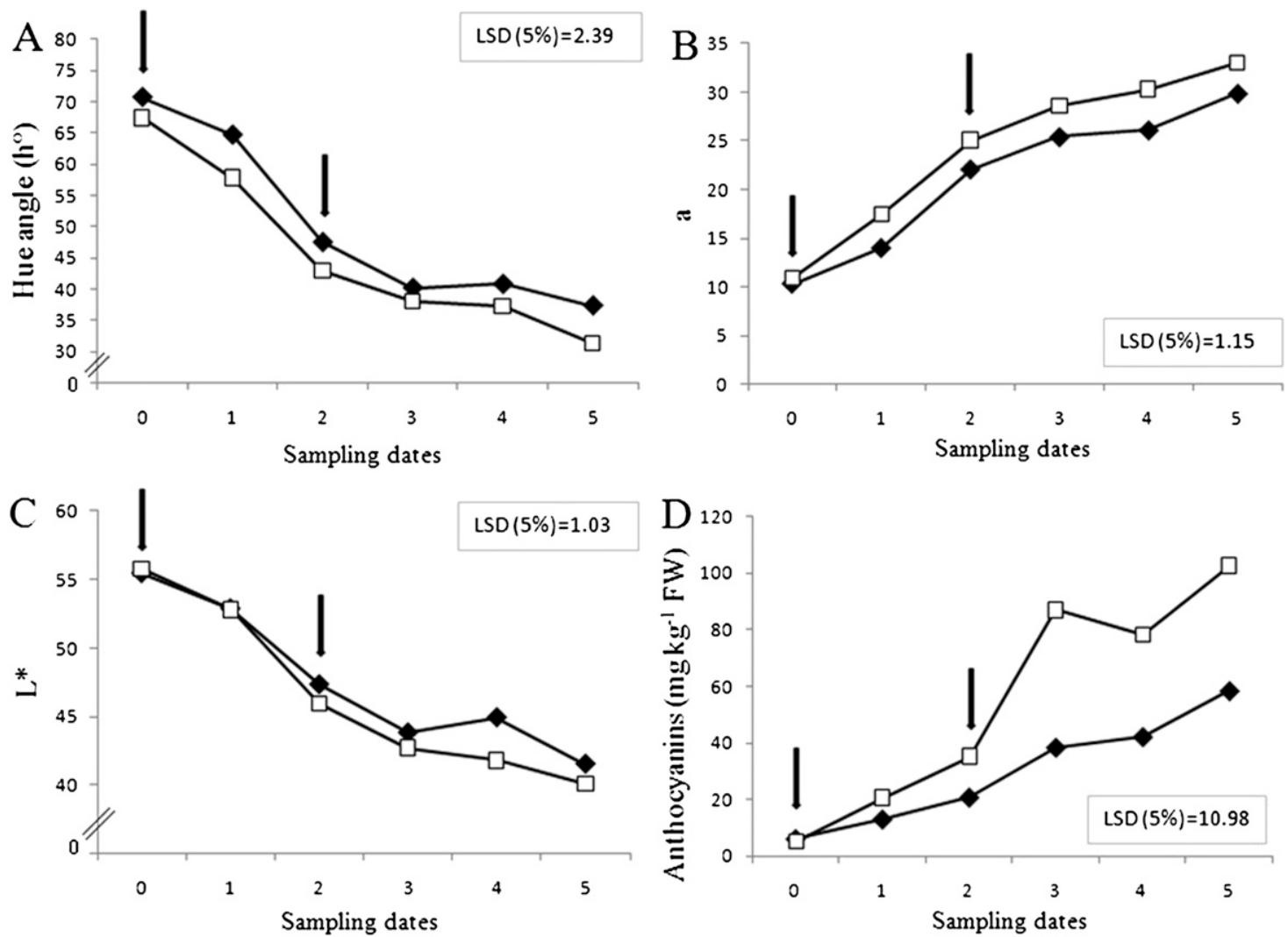

Fig. 1. Colorimetric parameters hue angle $\left(h^{\circ}\right)(\mathbf{A}), a^{*}(\mathbf{B}), L^{*}(\mathbf{C})$, and the concentration of anthocyanins of the 'Braeburn' apples $(\mathbf{D})$ treated with Phostrade Ca $(\square)$ and control $(\checkmark)$ at different sampling dates $(\mathrm{n}=20)$. Least significant differences (LSD) (5\%) of the treatment are presented. Arrows indicate treatment application dates but measurements have been done before the respective application. $\mathrm{FW}=$ fresh weight. 
the treated apple skin contained $102.57 \mathrm{mg}$ anthocyanins per kg FW, whereas the concentration in the control was only $58.52 \mathrm{mg}$ per kg FW.

Before the first application (sampling date 0 ), no significant differences in the total anthocyanin concentration between the treated and untreated apples were observed. Pho $\mathrm{Ca}$ significantly increased anthocyanin accumulation. During the 5 weeks of ripening, the anthocyanin level in the treated apples increased almost 20-fold, whereas the control increased only nine times. The average value for the treated apples was $64.72 \mathrm{mg} \cdot \mathrm{kg}^{-1} \mathrm{FW}$, whereas average of the control was 34.66 $\mathrm{mg} \cdot \mathrm{kg}^{-1} \mathrm{FW}(P=0.00001)$. Cyanidin 3-Ogalactoside was the main cyanidin glycoside in the apple skin, representing $80 \%$ to $86 \%$ of the total anthocyanins. Concentrations at commercial harvest were 82.02 in the treated apples and $47.33 \mathrm{mg} \cdot \mathrm{kg}^{-1} \mathrm{FW}$ in the control. In addition, cyanidin 3-O-arabinoside, cyanidin 7- $O$-arabinoside, cyanidin 3- $O$-xyloside, and cyanidin 3-O-glucoside, which were present in smaller amounts, were also analyzed. Pho Ca significantly increased accumulation of all cyanidin glycosides and the power impact of treatment on all of them was very similar (Table 1).

Regarding the flavonols, quercetin 3-Ogalactoside (hyperin), quercetin 3-O-rutinoside (rutin), quercetin 3-O-rhamnoside (quercitrin), quercetin 3-O-arabinofuranoside, quercetin 3$O$-arabinopyranoside, quercetin 3-O-glucoside (isoquercitrin), and quercetin 3- $O$-xyloside (reynoutrin) were analyzed. Among them, quercetin 3-O-galactoside represented the largest share, accounting for $\approx 40 \%$ of the total amount analyzed, whereas the concentration of quercetin 3-O-arabinopyranoside was the lowest. Similar findings were previously reported by Bizjak et al. (2012) with the difference that the concentrations were lower in the present study.

Pho $\mathrm{Ca}$ also significantly enhanced the formation of flavonols, which increased during the advanced ripening when comparing the zero and the fifth sampling dates (Fig. 2B). However, the difference between treated and untreated apples was less significant than in the case of anthocyanins. During the 5 weeks of ripening, the average values of total flavonols $\left(\mathrm{mg} \cdot \mathrm{kg}^{-1} \mathrm{FW}\right)$ were 410.98 for the treated apples and 337.14 for the control $(P=$

Table 1. Concentration of analyzed phenolics $\left(\mathrm{mg} \cdot \mathrm{kg}^{-1} \mathrm{FW}\right)$ and total phenolic content $(\mathrm{mg} \mathrm{GAE} / \mathrm{kg} \mathrm{FW})$ in the skin of apples treated with the Phostrade $\mathrm{Ca}$ and control. ${ }^{\mathrm{z}}$

\begin{tabular}{lcrc}
\hline & Phostrade Ca & Control & $P$ Value \\
\hline Cyanidin 3-galactoside & 49.59 & 28.03 & 0.000002 \\
Cyanidin 3-arabinoside & 5.08 & 2.59 & 0.000002 \\
Cyanidin 3-glucoside & 0.91 & 0.45 & 0.000001 \\
Cyanidin 3-xyloside & 2.14 & 1.13 & 0.000001 \\
Cyanidin 7-arabinoside & 4.75 & 2.45 & 0.000002 \\
Quercetin 3-galactoside & 166.83 & 124.25 & 0.0133 \\
Quercetin 3-glucoside & 39.77 & 28.48 & 0.0031 \\
Quercetin 3-rutinoside & 14.66 & 8.90 & 0.0004 \\
Quercetin 3-arabinofuranoside & 53.95 & 44.17 & 0.0339 \\
Quercetin 3- arabinopyranoside & 4.85 & 3.07 & 0.0007 \\
Quercetin 3-xyloside & 75.17 & 59.23 & 0.0154 \\
Quercetin 3-rhamnoside & 68.28 & 67.59 & 0.90 \\
Hydroxycinnamic acids & 33.27 & 31.75 & 0.57 \\
Flavonols & 362.89 & 336.84 & 0.35 \\
Dihydrochalcones & 72.71 & 68.35 & 0.27 \\
Total phenolic content & 1197.08 & 1213.38 & 0.70 \\
\hline
\end{tabular}

${ }^{\mathrm{z}}$ The presented data are the average values of five replicates at five sampling dates $(\mathrm{n}=25)$. Corresponding $P$ values of the treatment are also listed.

$\mathrm{FW}=$ fresh weight; $\mathrm{GAE}=$ gallic acid equivalents.
0.04). The influence of Pho Ca was noticed in all individual quercetin-glycosides, except quercetin 3-O-rhamnoside. The most pronounced was in the case of quercetin 3$O$-arabinopyranoside and quercetin 3-Orutinoside (Table 1).

No significant influence of treatment was observed either in the case of the total phenolic content or in the levels of hydroxycinnamic acids, flavonols, and dihydrochalcones (Table 1), although in the treated apples, an increase in flavonols after the second application of the Pho Ca was detected (data not shown).

Among sugars, the highest sugar concentration was fructose, representing up to $55 \%$ of the total sugars followed by sucrose, glucose, and few sorbitol. Our results are in accordance with those obtained by Veberic et al. (2007).

Before the first application of Pho $\mathrm{Ca}$ (sampling date 0 ), there were no differences in individual and total sugar concentration in apples that were later subjected to different treatments. Analyzing the sampling dates 0 and 1 , a significant interaction was observed in the case of sucrose $(P=0.02)$, whereas in the case of glucose $(P=0.08)$, fructose $(P=0.09)$, and total sugar concentration $(P=0.06)$, an interaction was marginally significant. The results obtained indicate that the first application of the Pho $\mathrm{Ca}$ had a significant effect on the synthesis of sugars in the treated apples. In the next 4 weeks of ripening (sampling dates 1 to 5), the sugars showed a similar accumulation pattern in both treatments (Fig. 2A). However, a significantly higher concentration of all the individual sugars, except fructose in the treated apples, was detected (Table 2). During ripening, the level of sucrose and glucose was significantly and positively $(P \leq 0.0002)$ correlated with the total anthocyanin concentration. The correlation between sucrose and anthocyanins was closer $(r=0.53)$ than between glucose and anthocyanins $(r=0.50)$.

The effect of the Pho Ca was also pronounced in the amount of total sugars. Over the 5 weeks of ripening, an average total sugar concentration $\left(\mathrm{mg} \cdot \mathrm{kg}^{-1} \mathrm{FW}\right)$ in the treated apples was 101.1 and 94.97 in control apples
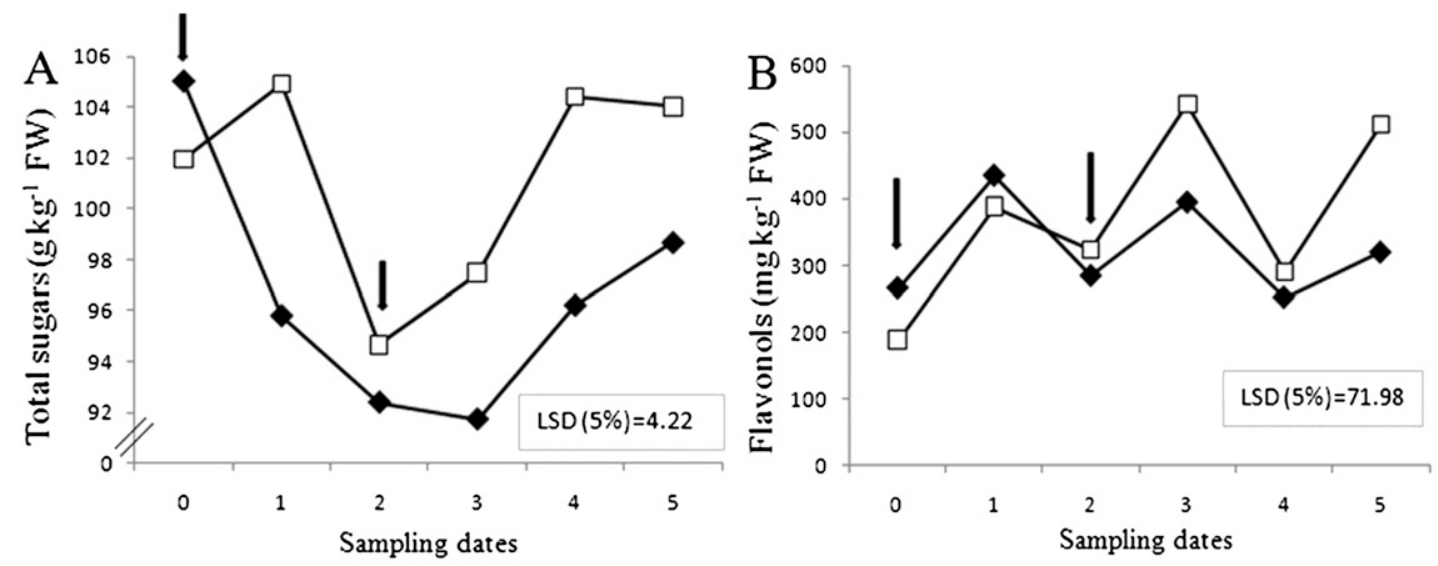

Fig. 2. The concentration of total sugars (A) and flavonols (B) in apples treated with Phostrade Ca $(\square)$ and control $(\diamond)$ at different sampling dates (n $=5$ ). Least significant differences (LSD) (5\%) of the treatment are presented. Arrows indicate treatment application dates but samples have been taken before the respective application. $\mathrm{FW}=$ fresh weight. 
$(P=0.0054)$. Regarding the amount of malic and citric acid, no influence of the $\mathrm{Pho} \mathrm{Ca}$ treatment was detected (Table 2).

During the 5 weeks of ripening, no significant changes in PAL $(P=0.76)$ and CHS/ CHI $(P=0.77)$ activities were detected (Fig. 3A-B). However, an increase in FHT and DFR activities $(P<0.001)$ was observed (Fig. 3C-D). At commercial harvest, the DFR activity was almost 2-fold and FHT activity almost 4-fold higher than at the beginning of advanced ripening (sampling

Table 2. Concentration of individual sugars (mg. $\left.\mathrm{kg}^{-1} \mathrm{FW}\right)$, malic and citric acid (mg. $\mathrm{kg}^{-1}$ FW) in the fruit of apples treated with Phostrade $\mathrm{Ca}$ and the control. ${ }^{\mathrm{z}}$

\begin{tabular}{lccl}
\hline & Phostrade Ca & Control & $P$ Value \\
\hline Fructose & 50.86 & 50.17 & 0.52 \\
Sucrose & 36.22 & 33.22 & 0.0048 \\
Glucose & 9.90 & 8.06 & 0.0017 \\
Sorbitol & 4.12 & 3.44 & 0.0093 \\
Malic acid & 5.03 & 5.12 & 0.60 \\
Citric acid & 0.91 & 0.96 & 0.20 \\
\hline
\end{tabular}

${ }^{\mathrm{z}}$ The presented data are the average values of five replicates at five sampling dates $(\mathrm{n}=25)$. Corresponding $P$ values of the treatment are also listed.

$\mathrm{FW}=$ fresh weight.
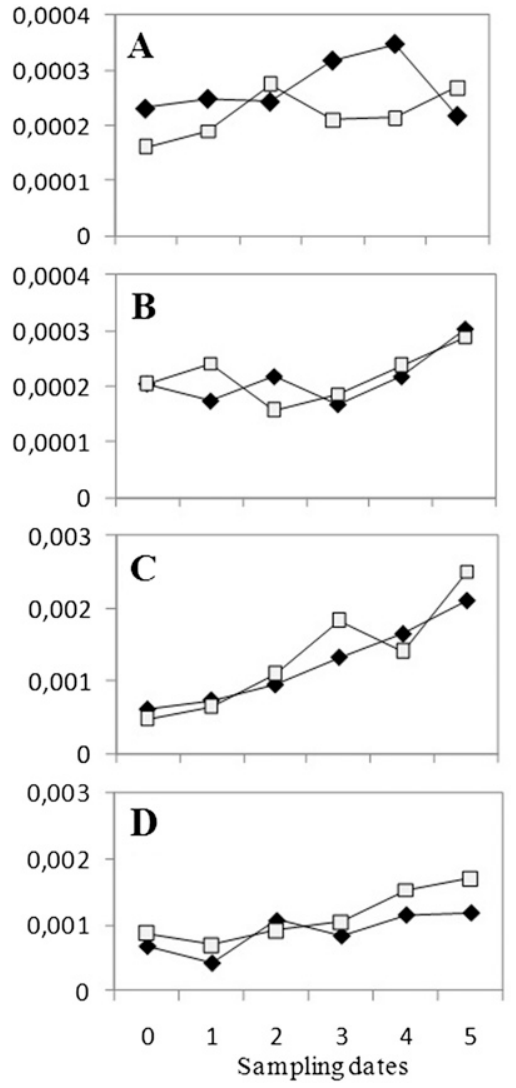

Fig. 3. Changes in enzyme activity (nkat. $\mathrm{g}^{-1} \mathrm{FW}$ ) of PAL (A), CHS (B), FHT (C), and DFR (D) in 'Braeburn' apples treated with Pho $\mathrm{Ca}(\square)$ and control $(\checkmark)$ at different sampling dates. $\mathrm{FW}=$ fresh weight; PAL = phenylalanine ammonia lyase; CHS = chalcone synthase; FHT = flavanone-3-hydroxylase; DFR = dihydroflavonol 4-reductase. date 0). FHT and DFR were significantly correlated with anthocyanin accumulation $(P<00001)$. The correlation between the anthocyanins and FHT $(r=0.70)$ was closer than between the anthocyanins and DFR $(r=0.61)$.

The significant influence of Pho Ca was seen only in the case of DFR $(P=0.01)$, in which the average activity (nkat. $\mathrm{g}^{-1} \mathrm{FW}$ ) during ripening in the treated apples $(0.001173)$ was $25.6 \%$ higher than the control ones ( 0.000934$)$. Slightly higher activity was noticed also by FHT; however, the difference was not significant $(P=0.35)$.

Before the first application (sampling date 0 ), the leaf $\mathrm{P}$ concentration in the control $\left(1.67 \mathrm{~g} \cdot \mathrm{kg}^{-1}\right)$ as well as in the treated leaves $\left(1.41 \mathrm{~g} \cdot \mathrm{kg}^{-1}\right)$ was under the critical value of $1.8 \mathrm{~g} \cdot \mathrm{kg}^{-1}$ proposed by Bergmann (1992) (Fig. 4). The measured values were similar to those in 'Jonagold' apple leaves reported by Wojcik and Wojcik (2007). The foliar application of the Pho Ca significantly increased the amount of $\mathrm{P}$ in the leaves of the treated apples. At commercial harvest, $28 \%$ higher $\mathrm{P}$ concentration in the treated leaves was detected when compared with the amount measured before the first application reaching the value of the critical concentration of $1.8 \mathrm{~g} \cdot \mathrm{kg}^{-1}$. However, in the control apples, almost a $10 \%$ lower amount compared with the first sampling date was observed. Regarding the amount of $\mathrm{Ca}$ in the leaves, no significant influence of the Pho Ca treatment was detected (data not shown).

\section{Discussion}

Application of Pho $\mathrm{Ca}$ significantly increased parameter $a^{*}$ and lowered the hue angle and lightness (Fig. 1). The improvement in the apple skin color as a result of foliar sprays of P-containing compounds has also been documented in several apple cultivars, including 'Starking Delicious' (GómezCordovés et al., 1996; Larrigaudiere et al., 1996), 'Fuji' (Li et al., 2002), 'Elstar' (Funke and Blanke, 2006), and 'Jonagold' (Wojcik and Wojcik, 2007). In the first three cited studies, the positive effect of foliar P applications on the fruit color was related to increased skin anthocyanin concentration, whereas in the studies of Funke and Blanke (2006) and Wojcik and Wojcik (2007), the apple color improvement was evaluated with the percentage of red blush.

In our study, the onset of rapid anthocyanin formation occurred between the second and the third sampling dates, $\approx 3$ weeks before the commercial harvest (Fig. 1D). Similar findings were also reported by Awad and de Jager (2002) who detected rapid color formation in 'Jonagold' apples $\approx 20 \mathrm{~d}$ before the harvest.

Two applications of $\mathrm{Pho} \mathrm{Ca}$ also increased synthesis of anthocyanins and flavonols (Figs. $1 \mathrm{D}$ and $2 \mathrm{~B}$ ). Our results are similar to those of Li et al. (2002) who reported that accumulation of anthocyanins and flavonols in Seniphostreated 'Fuji' apples was much higher than the untreated fruit. Seniphos, a $\mathrm{P}-\mathrm{Ca}$ mixture $\left(23.6 \% \mathrm{w} / \mathrm{w} \mathrm{P}_{2} \mathrm{O}_{5}, 3 \% \mathrm{w} / \mathrm{w} \mathrm{Ca}\right.$, and $3 \% \mathrm{w} / \mathrm{w}$ nitrogen), has almost the same chemical composition as $\mathrm{Pho} \mathrm{Ca}$, which was used in our experiment. Higher accumulation of anthocyanins in Seniphos-treated apples was reported also in the study of Gómez-Cordovés et al. (1996) and Larrigaudiere et al. (1996) in 'Starking Delicious' apples. However, Awad and de Jager (2002) found no influence of Seniphos on the formation of anthocyanins and quercetin 3-glycosides in 'Jonagold' apples.

Generally, no significant effect of $\mathrm{Pho} \mathrm{Ca}$ on the accumulation of other classes of flavonoids and total phenolics was observed (Table 1); however, an increase of the flavonols in the treated apples after the second application (data not shown) corresponded well to the increase of DFR activity at the late stage of ripening (Fig. 3D).

So far the mechanism by which P-containing compounds affect the coloration of apples has been studied poorly and remains unclear. $\mathrm{Li}$ et al. (2002) reported that foliar spraying with the P-containing compound Seniphos greatly increased the PAL and $\mathrm{CHI}$ activities, suggesting that these enzymes are closely related to anthocyanin accumulation. The rapid increase of PAL activity directly related to the increase of anthocyanin biosynthesis was reported also by Larrigaudiere et al. (1996) in 'Starking Delicious' apples. However, PAL

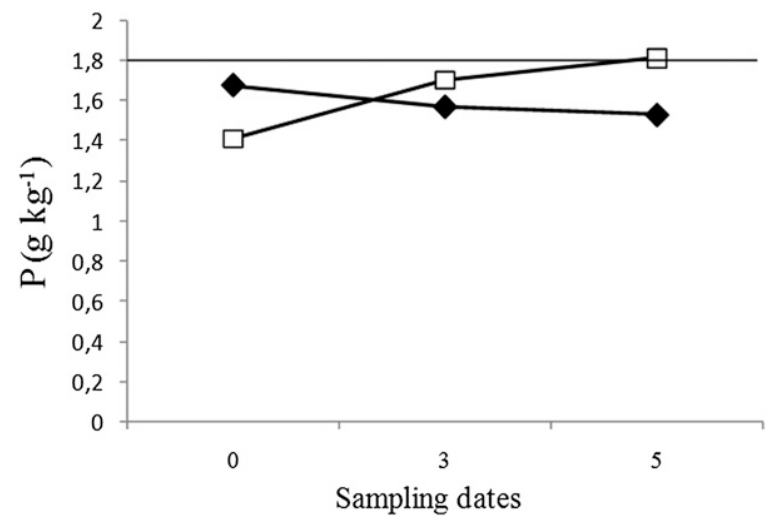

Fig. 4. Phosphorus (P) levels in the leaves of apples treated with the Phostrade Ca ( $\square$ ) and control ( $\checkmark)$ at different sampling dates. Horizontal line presents the critical content for phosphor (according to Bergmann, 1992). 
may not be a key enzyme during fruit maturation in apple (Lister and Lancaster, 1996; Saure, 1990) and CHS is not a regulatory enzyme in anthocyanin biosynthesis (Ju et al., 1995). In our study no increase in activities of these enzymes was detected (Fig. $3 \mathrm{~A}-\mathrm{B})$, suggesting that PAL and $\mathrm{CHS} / \mathrm{CHI}$ were not decisive for the increased anthocyanin accumulation. However, we found an increase in FHT and DFR, which was significantly correlated with the observed anthocyanin accumulation. The increase in DFR activity in treated apples corresponded well to the increase in flavonol concentration after the second application of Pho $\mathrm{Ca}$ (data not shown). Higher FHT and DFR activity in the last stages of ripening was observed also in the study of Slatnar et al. (2012) in 'Florina' apples.

The accumulation of anthocyanins and flavonols is also dependent on temperature (Arakawa, 1991) and on a regular supply of sugars in the plant (Lueangprasert et al., 2010). It has been suggested that low temperatures may reduce the loss of sugars in the skin by reducing respiration, which allows more sugar substrate for anthocyanin production (Lancaster, 1992). In our experiment, the amount of total sugars decreased at the beginning of the advanced ripening and at commercial harvest somehow reached the value measured at the beginning of the sampling (Fig. 2A). The decrease could be the result of the weather conditions, specifically high day and night temperatures, which stimulated the respiration processes in fruits. Approximately 3 weeks before the harvest, the night temperatures dropped, whereas day temperatures still remained quite high (Fig. 5). Just the drop in night temperatures may have reduced the loss of sugars in the skin of apples and thus stimulated anthocyanin biosynthesis. Rapid anthocyanin formation observed in our study at that time (Fig. 1D) confirms the mentioned hypothesis. Cold night temperatures followed by warm day temperatures have already been reported to stimulate anthocyanin synthesis in some apple cultivars (Reay, 1999). It could be speculated that a higher accumulation of anthocyanins in the Pho Ca-treated apples could be the result of higher sugar concentration, especially those of sucrose and glucose (Table 2). The positive correlation between the sucrose and the anthocyanins and glucose and anthocyanins confirms that assumption. The stimulatory effects of sugars, especially sucrose, on anthocyanin biosynthesis have been already reported in several plant species, including Vitis vinifera cells (Vitrac et al., 2000), radish (Raphanus sativus) hypocotyls (Hara et al., 2003), mango (Magnifera indica Linn. cv. Mahajanaka) fruit exocarp (Lueangprasert et al., 2010), and Arabidopsis (Arabidopsis thaliana) seedlings (Teng et al., 2005).

In our study, the reason for higher synthesis of sugars in the treated apples could be the higher amount of $\mathrm{P}$ in the leaves of the treated apples (Fig. 4), because starch synthesis in the chloroplasts and transport of sugars across the chloroplast envelope into

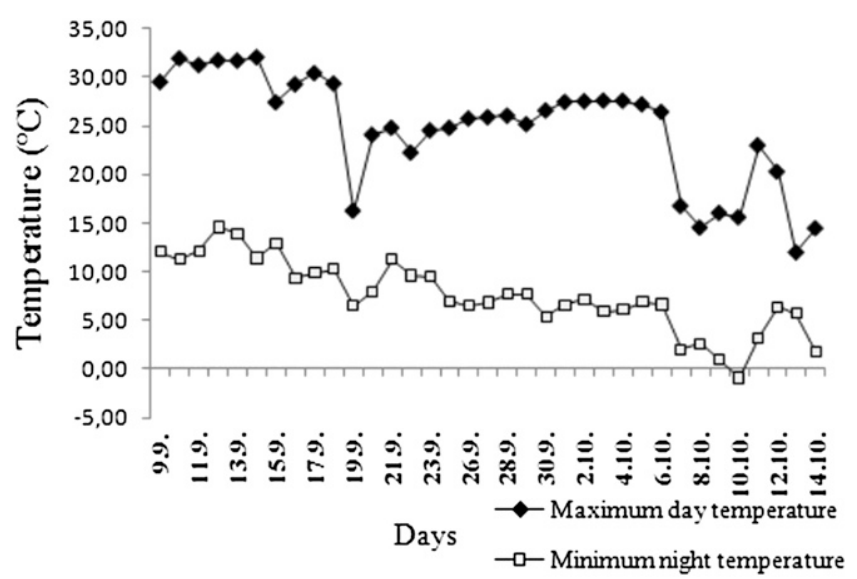

Fig. 5. Maximum day and minimum night temperatures during advanced fruit ripening recorded in the orchard of the Biotechnical faculty in Ljubljana in 2011.

the cytoplasm are directly controlled by the concentration of inorganic phosphate (Heldt et al., 1977). However, so far the importance of the $P$ and its influence on sugar concentration in apple fruit has been poorly investigated.

\section{Conclusions}

In the present study, we were able to demonstrate that two applications of the $\mathrm{Pho} \mathrm{Ca}$ $\approx 5$ weeks before harvest can markedly enhance the synthesis of anthocyanins and improve the red coloration of 'Braeburn' apple skin. In addition, the synthesis of most of the flavonols was also increased. Through the analysis of sugars and enzymatic activities, we were capable to evaluate some of the possible mechanisms by which the P-containing compounds affect the red coloration of apples. However, the color development is a complicated process; therefore, in the future, further research is needed to determine the function of $\mathrm{P}$, sugar levels, and enzyme activities on red coloration of apple skin and thus get better insight in the mode of action of the Pho $\mathrm{Ca}$ or similar P-containing compounds.

\section{Literature Cited}

Arakawa, O. 1991. Effect of temperature on anthocyanin accumulation in apple fruit as affected by cultivar, stage of fruit ripening and bagging. J. Hort. Sci. 66:763-768.

Awad, M.A. and A. de Jager. 2002. Formation of flavonoids, especially anthocyanin and chlorogenic acid in 'Jonagold' apple skin: Influences of growth regulators and fruit maturity. Sci. Hort. 93:257-266.

Bae, R. and K. Kim. 2006. Anatomical observations of anthocyanin rich cells in apple skins. HortScience 41:733-736.

Bergmann, W. (ed.). 1992. Nutritional disorders of plants: Development, visual and analytical diagnosis. Gustav Fischer Verlag, Jena, Germany.

Bizjak, J., J. Jakopic, A. Slatnar, F. Stampar, K. Stich, H. Halbwirth, P. Zadravec, and R. Veberic. 2012. Late prohexadione-calcium application on maturing apple cv. 'Braeburn' fruit reduces anthocyanins and alters the phenolic content. Europ. J. Hort. Sci. 77:154-162.
Blanke, M.M. 2008. Alternatives to reflective mulch cloth (ExtendayTM) for apple under hail net? Sci. Hort. 116:223-226.

Chalmers, D.J. and J.D. Faragher. 1977. Regulation of anthocyanin synthesis in apple skin. I. Comparison of the effects of cycloheximide, ultraviolet light, wounding and maturity. Aust. J. Plant Physiol. 4:111-121.

Espley, R.V., R.P. Hellens, J. Putterill, D.E. Stevenson, S. Kutty-Amma, and A.C. Allan. 2007. Red coloration in apple fruit is due to the activity of the MYB transcription factor, MdMYB10. Plant J. 49:414-427.

Funke, K. and M.M. Blanke. 2006. Farb- und Fruchtqualitätsverbesserung bei Äpfeln mit Monophosphat und Extenday. Erwerbs-Obstbau 48:121-129.

Gómez-Cordovés, C., F. Varela, C. Larrigaudiere, and M. Vendrell. 1996. Effect of ethephon and Seniphos treatments on the anthocyanin composition of Starking apples. J. Agr. Food Chem. 44:3449-3452.

Gosch, C., I. Puhl, H. Halbwirth, K. Schlangen, S. Roemmelt, C. Andreotti, G. Costa, T.C. Fischer, D. Treutter, K. Stich, and G. Forkmann. 2003. Effect of prohexadione-Ca on various fruit crops: Flavonoid composition and substrate specificity of their dihydroflavonol 4-reductases. Europ. J. Hort. Sci. 68:144-151.

Greer, D.H. 2005. Non-destructive chlorophyll fluorescence and colour measurements of 'Braeburn'and 'Royal Gala' apple (Malus domestica) fruit development throughout the growing season. N. Z. J. Crop Hort. Sci. 33:413-421.

Hara, M., K. Oki, K. Hoshino, and T. Kuboi. 2003. Enhancement of anthocyanin biosynthesis by sugar in radish (Raphanus sativus) hypocotyl. Plant Sci. 164:259-265.

Heldt, H.W., C. Ja Chong, D. Maronde, A. Herold, Z.S. Stankovic, D.A. Walker, A. Kraminer, M.R. Kirk, and U. Heber. 1977. Role of orthophosphate and other factors in the regulation of starch formation in leaves and isolated chloroplasts. Plant Physiol. 59:1146-1155.

Hudina, M. and F. Stampar. 2011. Effect of fruit bagging on quality of 'Conference' pear (Pyrus communis L.). Europ. J. Hort. Sci. 76:176-181.

Iglesias, I., J. Salvia, L. Torguet, and C. Cabús. 2002. Orchard cooling with overtree microsprinkler irrigation to improve fruit colour and quality of 'Topred Delicious' apples. Sci. Hort. 93:39-51.

Jakopic, J., F. Stampar, and R. Veberic. 2010. Influence of hail net and reflective foil on cyanidin glycosides and quercetin glycosides 
in 'Fuji' apple skin. HortScience 45:14471452.

Ju, Z., C. Liu, and Y. Yuan. 1995. Activities of chalcone synthase and UDPGgal: Flavonoid3-O-glycosyltransferase in relation to anthocyanin synthesis in apple. Sci. Hort. 63:175-185.

Lancaster, J.E. 1992. Regulation of skin color in apples. Crit. Rev. Plant Sci. 10:487-502.

Larrigaudiere, C., E. Pinto, and M. Vendrell. 1996. Differential effects of ethephon and Seniphos on color development of 'Starking Delicious' apple. J. Amer. Soc. Hort. Sci. 121:746750.

Li, Z., H. Gemma, and S. Iwahori. 2002. Stimulation of 'Fuji' apple skin color by ethephon and phosphorus-calcium mixed compounds in relation to flavonoid synthesis. Sci. Hort. 94:193199.

Lister, C.E. and J.E. Lancaster. 1996. Developmental changes in enzymes of flavonoid biosynthesis in the skins of red and green apple cultivars. J. Sci. Food Agr. 71:313-320.

Lister, C.E., J.E. Lancaster, K.H. Sutton, and J.R.L. Walker. 1994. Developmental changes in the concentration and composition of flavonoids in skin of a red and a green apple cultivar. J. Sci. Food Agr. 64:155-161.

Lueangprasert, K., J. Uthaibutra, K. Saengnil, and O. Arakawa. 2010. The effects of sugar application on the concentrations of anthocyanin and flavonol of 'Mahajanaka' Mango (Magnifera indica Linn. cv. Mahajanaka). Fruit. Chiang Mai J. Sci. 37:355-362.
Marks, S.C., W. Mullen, and A. Crozier. 2007. Flavonoid and chlorogenic acid profiles of English cider apples. J. Sci. Food Agr. 87: 719-728.

McGuire, R.G. 1992. Reporting objective colour measurements. HortScience 27:1254-1255.

Mikulic-Petkovsek, M., A. Slatnar, F. Stampar, and R. Veberic. 2010. The influence of organic/ integrated production on the content of phenolic compounds in apple leaves and fruits in four different varieties over a 2-year period. J. Sci. Food Agr. 90:2366-2378.

Mikulic-Petkovsek, M., F. Stampar, and R. Veberic. 2007. Parameters of inner quality of the apple scab resistant and susceptible apple cultivars (Malus domestica Borkh.). Sci. Hort. 114:37-44.

Reay, P.F. 1999. The role of low temperatures in the development of the red blush on apple fruit ('Granny Smith'). Sci. Hort. 79:113-119.

Saure, M.C. 1990. External control of anthocyanins formation in apple. Sci. Hort. 42:181-218.

Singleton, V.L. and J.A. Rossi. 1965. Colorimetry of total phenolics with phosphomolybdicphospholungistic acid reagents. Amer. J. Enol. Viticult. 16:144-158.

Slatnar, A., M. Mikulic-Petkovsek, H. Halbwirth, F. Stampar, K. Stich, and R. Veberic. 2010. Response of the phenylpropanoid pathway to Venturia inaequalis infection in maturing fruit of 'Braeburn' apple. J. Hort. Sci. Biotechnol. $85: 465-472$.

Slatnar, A., M. Mikulic-Petkovsek, H. Halbwirth, F. Stampar, K. Stich, and R. Veberic. 2012.
Polyphenol metabolism of developing apple skin of a scab resistant and a susceptible apple cultivar. Trees (Berl.) 26:109-119.

Telias, A., D. Rother, and E. Hoover. 2008. Plant and environmental factors influencing the pattern of pigment accumulation in 'Honeycrisp' apple peels, using a novel color analyzer software tool. HortScience 43:1441-1445.

Teng, S., J. Keurentjes, L. Bentsink, M. Koornneef, and S. Smeekens. 2005. Sucrose-specific induction of anthocyanin biosynthesis in Arabidopsis requires the MYB75/PAP1 gene. Plant Physiol. 139:1840-1852.

Treutter, D. 2001. Biosynthesis of phenolic compounds and its regulation in apple. Plant Growth Regulat. 34:71-89.

Veberic, R., P. Zadravec, and F. Stampar. 2007. Fruit quality of 'Fuji' apple (Malus domestica Borkh.) strains. J. Sci. Food Agr. 87:593-599.

Vitrac, X., F. Larronde, S. Krisa, A. Decendit, G. Deffieux, and J.M. Merillon. 2000. Sugar sensing and $\mathrm{Ca}^{2+}$-calmodulin requirement in Vitis vinifera cells producing anthocyanins. Phytochem. 53:659-665.

Whale, S.K., Z. Singh, M.H. Behboudian, J. Janes, and S.S. Dhaliwal. 2008. Fruit quality in 'Cripp's Pink' apple, especially colour, as affected by preharvest sprays of aminoethoxyvinylglycine and ethephon. Sci. Hort. 115:342-351.

Wojcik, P. and M. Wojcik. 2007. Response of mature phosphorous-deficient apple trees to phosphorous fertilization and liming. J. Plant Nutr. 30:1623-1637. 